and tends to ascribe power to men more often than women, may contribute to inequalities of opportunity between the sexes. "It is through language that we [women] come to know our subordinate place in the world."

Sexism is deeply embedded in the English language, and various ways of avoiding sex biased writing have been suggested.' These have ranged from the use of plural pronouns in the singular and the avoidance of words containing "man" to the creation and use of neologisms such as "himorher." None of the solutions is perfect; which is optimal depends on the context. ${ }^{5} \mathrm{By}$ choosing not to use any of the options we merely perpetuate an imprecise and potentially offensive usage.

1 Burkhart S. Sexism in medical writing. BMF 1987;295:1585

2 Cameron D. Feminism and linguistic theory. London: Macmillan, 1985.

3 Hofstadter DR. A person paper on purity in language. In: Metamagical themas. Harmondsworth: Penguin, 1986

4 Vetterling-Braggin M. Sexist language: a modern philosophical analysis. Totowa, New Jersey: Littlefield, Adams, 1981.

5 Horne EM. Sexism and the plural in medical writing. BMf 1988;296:431.

(Accepted 21 fanuary 1992)

\title{
Hospital admission and the start of benzodiazepine use
}

\section{Surendrakumar, M Dunn, C J C Roberts}

Bristol Royal Infirmary, Bristol BS2 8HW

D Surendrakumar, medical student

M Dunn, principal

pharmacist

C J C Roberts, consultant

clinical pharmacologist

Correspondence to:

Dr Roberts.

BMF 1992;304:881
Despite awareness of the adverse effects of benzodiazepines and their potential for dependence, ${ }^{1} 23.2$ million NHS prescriptions for them were issued in $1988 . .^{2}$ Although most prescriptions are issued from general practice, ${ }^{3}$ the contribution of hospital prescribing to the initiation of benzodiazepine use should be acknowledged..$^{24} \mathrm{We}$ examined whether admission to hospital continues to be a factor in patients starting on these drugs.

\section{Methods and results}

Pharmacists at three general hospitals recorded patients supplied with benzodiazepines on discharge from hospital for a two week period in September 1990. Psychiatric cases were excluded. With the consultant's permission 58 sets of notes from the 65 cases notified were scrutinised.

The mean (SD) age of the patients was 74 (11) years. Thirty five $(60 \%)$ were male. In $38(65 \%)$ cases the consultant was a physician, in $16(28 \%)$ a surgeon, and in four (7\%) a cancer therapist. The benzodiazepines used were temazepam (44), nitrazepam (4), diazepam (3), triazolam (3), lorazepam (2), clonazepam (1), and chlordiazepoxide (1).

Before admission to hospital 17 patients, 14 of whom had been under physicians and three under surgeons, had not used benzodiazepines, 12 patients had started taking benzodiazepines during previous hospita admissions, so in all 29-half the group-had started in hospital. Seventeen had started in the community; in 12 cases this was not possible to ascertain.

The rationale for benzodiazepine use was not documented in 22 cases. In eight the drug had been prescribed at the time of the admission clerking. In 26 cases it was to aid sleeping, in eight for anxiety, in three to assist in the management of intractable pain. In 10 of the 17 new users it was to aid sleep, in one for anxiety, and one for pain.

Excluding the 17 new users, five had been taking these drugs for up to two months, seven up to a year, and 20 for more than one year. In the 10 patients who had taken benzodiazepines long term (more than two years) evidence of dependence was found in eight. Attempts to stop the drugs had been made in five patients, and withdrawal symptoms had occurred in two.

Three patients were supplied with benzodiazepines despite evidence in the notes that the patients had not actually taken them during the admission. One of these patients had been diagnosed as having Alzheimer's disease.

One patient had been given temazepam every night from the time of admission with a cerebrovascular accident throughout the course of a five month stay in hospital. He had not previously used the drug.

An 89 year old woman had been given temazepam for anxiety, lightheadedness, and giddiness. She was subsequently admitted with an accidental overdose.

\section{Comment}

The identification of 17 potential new users of benzodiazepines after admission to the general beds in one district in two weeks was higher than expected and is unacceptable. If the study is representative it implies a considerable potential risk for subsequent dependence.

These findings contrast with those of a survey during one week at St Bartholomew's Hospital, ${ }^{4}$ which found that no patient had benzodiazepine treatment initiated at the time of discharge. Trewin et al, however, found that $2 \%$ of admissions of elderly patients resulted in a discharge prescription for benzodiazepines. ${ }^{5}$ In Newcastle a six week study that included community follow up found 13 new users after hospital admission, but only three had been supplied at the time of discharge. ${ }^{2}$ Our study suggests that hospital prescribing continues to contribute to benzodiazepine use in the community as half the group had first been prescribed the drugs in hospital.

In addition to the inappropriate supply of drugs at the end of a hospital stay, poor prescribing was evident by the drug's apparently unwarranted use in an elderly demented patient and continuous use in a stroke victim. There was also clear evidence that benzodiazepine hypnotics were being prescribed at the time of admission, before an assessment of the need could have been made.

There is no room for complacency in hospitals regarding benzodiazepine prescribing. This study highlights the need for prescribing policies to be formulated and instituted.

1 Ashton $\mathrm{CH}$. Adverse effects of prolonged benzodiazepine use. Adverse Dru Reaction Bulletin 1986;118:440-3.

Edwards C, Bushnell JL, Ashton CH, Rawlins MD. Hospital prescribing and usage of hypnotics and anxiolytics. Br f Clin Pharmacol 1991;31:190-2.

3 Catalan J, Gath DH. Benzodiazepines in general practice: time for a decision. BMf 1985;290:1374-6.

Shan K, Nolan JA, Turner P, Jackson SHD. Prescription of benzodiazepines in a London teaching hospital. f R Soc Med 1990;83:306-7.

Trewin VF, Pearce V, Veitch GBA. Elderly patients at risk. British foumal of Pharmaceutical Practice 1986;8:359-63.

(Accepted 12 December 1991) 